\title{
1 AGE, ORIGIN, AND BIOGEOGRAPHY: UNVEILING THE FACTORS \\ 2 BEHIND THE DIVERSIFICATION OF DUNG BEETLES
}

3 Orlando Schwery ${ }^{1,2 *}$ and Brian C. O’Meara ${ }^{2}$

$4 \quad{ }^{1}$ New Mexico Consortium, Los Alamos, NM, USA

$5 \quad 2$ Department of Ecology and Evolutionary Biology, University of Tennessee, Knoxville, TN, 6 USA

$7 \quad *$ Corresponding author: oschwery@vols.utk.edu

8 Keywords: dung beetles, Scarabaeinae, diversification, speciation, extinction, macroevolution, 9 phylogenetics, biogeography

\section{Abstract}

12 The remarkable diversity and global distribution of dung beetles has long attracted the interest of

13 researchers. However, there is still an ongoing debate on their origin, the reasons behind their

14 diversity, and their path to global distribution. The two most prominent hypotheses regarding

15 their origin and biogeographic history involve either vicariance events after the breakup of

16 Gondwana, or an African origin and subsequent dispersal. One of the key reasons why the

17 question is still disputed is a dependence on knowing the age of the dung beetles - a Mesozoic

18 origin would favor the scenario of Gondwanan vicariance, a Cenozoic origin would suggest the

19 out-of-Africa scenario. To help settle this longstanding question, we provide a taxonomically

20 expanded phylogeny, with divergence times estimated under two calibration schemes suggesting

21 an older or younger origin respectively. Using model-based inference, we estimate the ancestral

22 area of the group and test for the influence of ranges on diversification rates. Our results support

23 the hypothesis of an old age for Scarabaeinae and Gondwanan origin but remain ambiguous

24 about the exact relation of range on lineage diversification. 


\section{Introduction}

27 Dung beetles are a remarkable group of insects. Their unusual lifestyle requiring the dung of

28 other animals to feed and reproduce gave rise to a host of morphological and behavioral

29 specializations, as adaptations to the various ecological peculiarities they face in their worldwide

30 distribution (Hanski \& Cambefort 1991). While their diversity of around 5,300 species is

31 comparatively modest among beetles, their dung-processing activity makes them one of the most

32 important groups of insects, both ecologically (Nichols et al. 2008) and economically (Losey \&

33 Vaughan 2006). Their unusual life history has attracted considerable interest of researchers, in

34 ecology and evolution (Hanski \& Cambefort 1991; Scholtz, Davis \& Kryger 2009), conservation

35 (Spector 2006), and even developmental biology (Moczek 2011). Despite that, key aspects

36 concerning their origin and the factors behind their diversity are still unknown and subject of

37 debate in the field. The ecology of extant species has been well studied (Hanski \& Cambefort

38 1991), but the main hindrance to understanding historical, evolutionary aspects of their biology

39 is the lack of a comprehensive and reliable phylogeny (Tarasov \& Génier 2015), and with that,

40 validation for their taxonomy (Tarasov \& Dimitrov 2016).

41 Probably the two most debated questions of dung beetle evolution revolve around their

42 geographic origin and what led to their current diversity and distribution. A relation to their

43 associated dung producers is suspected (Scholtz, Davis \& Kryger 2009; Gunter et al. 2016), but

44 disagreement exists over whether the success of dung beetles has always been an association

45 with mammals, or whether dinosaurs were involved early in their history. Regarding their

46 geographic origin and subsequent spread, the main competing hypotheses are whether it was

47 Gondwanan-vicariance (Davis, Scholtz \& Philips 2002) or dispersal out of Africa (Sole \&

48 Scholtz 2010). The answers to all these hypotheses partially hinge on the question of how old the

49 group is. It has long been debated whether Scarabaeinae are of Mesozoic or Cenozoic origin -

50 the former would make Gondwanan vicariance and feeding on dinosaur dung plausible, the latter

51 would rule it out. Earlier attempts to determine the age of dung beetles using various approaches

52 led to widely different estimates, ranging from mid Mesozoic to early Cenozoic (Hanski \&

53 Cambefort 1991; Scholtz \& Chown 1995; Krell 2000; Davis, Scholtz \& Philips 2002; Krell

54 2006). More recent attempts using phylogenies also ranged from Cretaceous to Eocene- 
55 Oligocene (Wirta, Orsini \& Hanski 2008; Ahrens, Schwarzer \& Vogler 2014; Mlambo, Sole \&

56 Scholtz 2015; Gunter et al. 2016), shifting the support for early and late origins of Scarabaeinae

57 over time (Scholtz, Davis \& Kryger 2009). At this time, the field is still divided: an old Mesozoic

58 origin of dung beetles, and with that a biogeographical scenario of Gondwanan vicariance and

59 subsequent dispersal has been supported by some studies (Davis, Scholtz \& Philips 2002; Gunter

60 et al. 2016; Gunter et al. 2018), whereas a young Cenozoic origin and therefore an out-of-Africa

61 dispersal scenario has been supported by others (Monaghan et al. 2007; Sole \& Scholtz 2010;

62 Davis, Scholtz \& Sole 2016).

63 To address these questions, we provide an extended phylogeny of Scarabaeinae, with divergence

64 times estimates based on calibrations reflecting two different assumptions of their maximal age.

65 We use this phylogeny and the inferred age of the group to address the question of their

66 geographical origin using model-based methods for ancestral range estimation; and the question

67 of how it relates to their lineage diversification using range-dependent diversification rate

68 estimation. In particular, focusing on their Gondwanan origin and subsequent dispersals to areas

69 of (what was formerly) Laurasia and Madagascar, we address the question of whether the

70 dispersal into new areas was promoting dispersal, or whether their place of origin is the main

71 source of diversification. Finally, we test a hypothesis that links dung beetle diversity to the dung

72 producers present in different regions (Davis \& Scholtz 2001; Scholtz, Davis \& Kryger 2009).

73 Specifically, linking beetle diversity to the size of mammal dung producers, and the diversity of

74 different dung types they produced, suggesting that areas with larger mammals and more diverse

75 droppings would allow for a more diverse dung beetle fauna.

\section{Materials and Methods}

\section{$77 \quad$ Phylogenetic Analysis}

78 We wrote a script in R (R Development Core Team 2014) using the packages reutils (Schöfl

79 2016) and seqinr (Charif et al. 2005) to query GenBank (Sayers et al. 2019) for any nucleotide

80 sequences matching the organism label "Scarabaeinae" and that carried either "COI", "16S",

81 "18S", "28S", or "CAD" in the title. We downloaded the resulting accessions using the packages

82 ape (Paradis, Claude \& Strimmer 2004) and insect (Wilkinson et al. 2018), removed any 
83 duplicates and saved them as FASTA files. The 28S accessions included both 28SD2 and 28SD3

84 sequences, which were sorted and aligned separately. The retrieved COI sequences largely

85 covered two adjacent regions of the gene, and since only few accessions covered both regions,

86 we decided to split them into two separate alignments (further called COI-1 and COI-2

87 respectively). If a marker had taxa with several accessions, the longest sequence was chosen

88 unless it proved to be clearly different from the other accessions for that taxon. Taxa which were

89 only determined to genus level were only included if they were the only representative of that

90 genus.

91 The accessions of the seven markers were aligned separately using AliView v.1.26 (Larsson

92 2014): They were aligned using MAFFT globalpair, and then visually inspected and adjusted

93 manually where necessary. During this process, any sequences that showed considerable

94 mismatch with the rest of the alignment were submitted to BLAST (Altschul et al. 1997) to

95 detect any mislabeled sequences from other organismal groups. Similarly, quick RAxML

96 (Stamatakis 2014) runs were performed for each aligned marker separately, and were tested for

97 generic monophyly and long branches. Generic monophyly was tested using the package

98 MonoPhy (Schwery \& O’Meara 2016). Long branches were determined using the package ips;

99 terminal branches were considered exceptionally long if their length was more than 0.25 times

100 the maximum tip height in the tree, or if the product of their length and height was more than two

101 times the interquartile range away from the third quartile of all tip length and tip height products

102 in the tree. Any taxa that stood out by branch length or placement were checked using BLAST as

103 well. The accession numbers of the sequences used in the final alignment can be found in Table

$104 \mathrm{~S} 1$.

105 Poorly aligned or divergent regions in each alignment were removed using Gblocks (Castresana

106 2000) (settings: minimum bases for conserved regions $>0.5 \mathrm{x}$ alignment length, minimum for

107 flanking regions >0.7x alignment length, maximum contiguous nonconserved sites: 8, minimum

108 block length: 4 (noncoding) or 5 (coding), gap positions allowed with > half of sequences having

109 gap). Finally, all alignments were concatenated using the package evobiR (Blackmon \& Adams

110 2015). Partitioning the alignment by each marker (the two marker parts in case of COI), we used

111 PartitionFinder v.2.1.1 (Lanfear et al. 2017) to determine the best substitution models for each 
112 partition, using the greedy algorithm (Lanfear et al. 2012), and PhyML (Guindon et al. 2010).

113 Additionally, the package ClockstaR (Duchene, Molak \& Ho 2014) was used to determine

114 whether the partitions should have different clock models.

115 Using the concatenated alignment and the determined substitution models, a maximum

116 likelihood phylogeny was constructed with RAxML v.8.2.4 (Stamatakis 2014), using the rapid

117 hill climbing algorithm with 100 rapid bootstrap samples. The ingroup and four clades that

118 would later be used for fossil calibrations (see below) were constrained to be monophyletic.

119 Because of branch support issues, we used the online implementation of RogueNaRok (Aberer,

120 Krompass \& Stamatakis 2013) to find potential rogue taxa. Taxa whose exclusion would lead to

121 a raw improvement of more than 1 were inspected and 136 sequences were eventually dropped

122 and a final RAxML tree was built from this reduced alignment. To account for weakly supported

123 clade relationships in subsequent analyses, ten sets of bootstrapped alignments were created, for

124 each of which a separate tree was built in the same manner as from the full alignment.

125 Monophyly on genus and tribe level was assessed for all trees using the R package MonoPhy

126 (Schwery \& O’Meara 2016).

\section{Divergence Time Estimation}

128 Reliable Scarabaeinae fossils that have recently been re-examined by Tarasov et al. (2016) were 129 chosen to calibrate tree nodes during divergence time estimation. Of the 35 fossils previously 130 assigned to Scarabaeinae, they considered only 21 to be assigned reliably on the basis of their

131 morphological characters. From among these, the earliest fossils with confident generic

132 placement were chosen for each genus that we could assign a node to. The minimal age of the

133 fossils was used as minimum constraint for the stem age of the corresponding clade. The oldest

134 reliable fossil dung beetle, Lobateuchus parisii, was used to constrain the subfamily, and the

135 minimal age estimate for Juraclopus rohendorfi, the oldest fossil of the family Scarabaeidae, was

136 used as the minimal age constraint for the crown of the whole tree.

137 In order to get times to constrain the maximal age of these clades, we consulted previous studies

138 that had estimated the age of Scarabaeinae. On the younger end of the spectrum, some studies

139 refer to Wirta, Orsini and Hanski (2008), or Mlambo, Sole and Scholtz (2015) for young 
140 estimates of the age of dung beetles (33.9ma or 56ma respectively). However, neither of those

141 estimates are particularly useful to calibrate the age of the whole group, as Wirta, Orsini and

142 Hanski (2008) focused on Helictopleurini of Madagascar, and Mlambo, Sole and Scholtz (2015)

143 exclusively on African dung beetles. While some more dated phylogenies of clades within the

144 subfamily exist, the only examples that include an age for the whole group are of higher taxa in

145 which the dung beetles are nested. Ahrens, Schwarzer and Vogler (2014) constructed a tree of

146146 taxa of Scarabaeoidea, in which the crown Scarabaeinae was estimated at 89.6ma (ranging

147 from 83.5-98.1ma), while Gunter et al. (2016) in a phylogeny of 445 taxa of Scarabaeoidea

148 estimated it to range from 118.8-131.6ma. While various studies estimated the ages within

149 Scarabaeoidea (Ahrens, Schwarzer \& Vogler 2014; McKenna et al. 2015; Toussaint et al. 2017),

150 the ages of Scarabaeinae and Scarabaeidae could not always be obtained from them -

151 consequently, we relied solely on Gunter et al. (2016) for an age estimate of Scarabaeidae

152 (116.85-199.64ma).

153 Because no clade can be older than the clade in which it is nested, we constrained the maximal

154 stem ages for all constrained genera (as well as the maximal crown age of all Scarabaeinae) to be

155 the maximal estimated age of the Scarabaeinae, and the maximal crown age of the whole tree

156 (being the stem age of Scarabaeinae) to be the maximal estimated age of Scarabaeidae. Given the

157 disagreement of estimated ages in the literature, we set up two different sets of constraints: an

158 'old' one, with the Scarabaeinae and Scarabaeidae ages as estimated by Gunter et al. (2016), and

159 a 'young' one, with the Scarabaeinae and Scarabaeidae ages as estimated by Ahrens, Schwarzer

160 and Vogler (2014) - with the latter actually being the age of Scarabaeoidea, due to the lack of

161 available ages for the actual Scarabaeidae (apart from that by Gunter et al. (2016)). While

162 McKenna et al. (2015) actually estimated a younger age for Scarabaeoidea, their estimate is

163 younger than the age of the oldest fossil of that group, which is why we chose to use the next

164 older estimate by Ahrens, Schwarzer and Vogler (2014) ranging from 167.2-181.8ma. The

165 different fossil constraints used can be seen in Table 2.

166 Those two sets of age constraints were then used to estimate divergence times for the ML tree

167 obtained through RAxML and all ten bootstrap trees, using penalized likelihood in treePL (Smith 
\& O'Meara 2012). We performed a thorough search with random cross validation, which was preceded by a preliminary run to estimate the best tuning parameters and smoothing factor.

\section{Occurrence Data and Ancestral Range Estimation}

171 We used the package rgbif (Chamberlain et al. 2016; Chamberlain \& Boettiger 2017) to

172 download occurrence data from GBIF (http://data.gbif.org) for all taxa determined to species

173 level. Using an R script, the retrieved records were cleaned from empty or invalid entries, with

174 regards to the basis of record, identification date, country and coordinates, and sets with unique

175 countries or coordinates per taxon respectively were made. Name validity of unavailable taxa

176 was checked using the package taxize (Chamberlain \& Szocs 2013), and eventually searched on

177 genus level. For any taxa that were still missing, occurrence information was searched for in the

178 literature.

179 We defined the areas taxa occur in as continents (Africa, Asia, Europe, North America, South

180 America, Oceania), and defined Madagascar as a separate area, given the high number of taxa

181 endemic to it (Miraldo, Wirta \& Hanski 2011). However, we did not define India as a separate

182 area, and considered it part of Asia. India has a peculiar tectonic history of initially staying

183 connected to Madagascar until breaking off around 87ma and drifting northwards to collide with

184 Asia around 55-43ma (Seton et al. 2012). Not explicitly including it as a separate area means a

185 major simplification for the model, but also ignoring potentially relevant possible scenarios. For

186 example, lineages that have entered India from Madagascar before their breakup, could have

187 been evolving in relative isolation there until coming into contact with Eurasia. However, we

188 suspect that testing that kind of scenario would require more detailed geographical resolution,

189 and thus may warrant a dedicated separate study.

190 Each taxon's range was defined as the one or several areas it occurred in, based on the collected

191 information from GBIF and the literature. Where information on continent was missing, it was

192 inferred from coordinates and countries of occurrence, and inconsistencies between these were

193 checked and corrected. Taxa occurring in many continents were inspected for the extent of

194 overlap and reliability of the records. In doing so, we also paid attention to species that were 
195 introduced to areas by humans, and removed such occurrences from the species' range, thereby

196 only assigning its presumed natural range.

197 Given the potential age of the group, it is conceivable that tectonic plate movement played a role

198 in their dispersal and distribution. We thus constructed a stratified dispersal matrix representing

199 the changing strength of dispersal barriers between the continents over time. We divided the last

200 200ma before the present into five time slices, following the tectonic events described in Seton et

201 al. (2012), stretching from 200-150ma (Pangaea intact), 150-110ma (breakup of Pangaea into

202 Gondwana and Laurasia, Madagascar breaking off of Africa, though still connected via

203 Antarctica), 110-50ma (breakup of Gondwana into Africa, Australia-Antarctica, and South

204 America, the latter still connected to Antarctica via a land bridge), 50-20ma (Australia separates

205 from Antarctica, Laurasia breakup into Laurentia and Eurasia (Hosner, Braun \& Kimball 2015),

206 South America properly disconnected from Antarctica (Reguero et al. 2014)), and 20-0ma (land

207 bridges (some temporary) establish at Beringia (Hosner, Braun \& Kimball 2015), the Isthmus of

208 Panama, and between Australia and Asia, and Eurasia and Africa).

209 Inspired by Toussaint, Bloom and Short (2017), we recognized dispersal barriers of different

210 strengths: 1) directly adjacent areas (barrier of strength 0), 2) areas connected by land bridge

$211(0.15), 3)$ areas separated by a small distance of water (0.25), and 4) by a large distance of water

212 (0.75). Having to pass through another area was considered a barrier of strength 0.5, and the case

213 of facing more than 3 barriers was assigned a strength of 0.95 ; the corresponding dispersal

214 multiplier was 1 - strength of barriers. The route of smallest resistance was picked for each

215 possible dispersal case, adding up the different barriers encountered (matrices see Table S4).

216 While it would make sense that different dispersal barriers at different times would affect the

217 dispersal dynamics of the group, it is also possible that only time differences or only dispersal

218 barriers did. Furthermore, the partially arbitrary choice of time intervals could affect the

219 inference as well. Thus, we also calculated averaged dispersal matrices to be used without time

220 stratification. For this purpose, the dispersal multipliers of each time slice were weighted by the

221 duration of that time slice relative to the total time from the beginning of that slice until the

222 present. These weighted multipliers were added up for each transition and then divided by the

223 sum of weights, so they would add to one. This weighting is intended to represent the fact that 
224 the more recent positioning of the continental plates should have had a higher impact on the 225 current distribution of extant taxa. Two matrices (for 3 and 4 time slices respectively, see Table

226 S5) were constructed that way, to be used for either the phylogeny dated with the younger or 227 older calibration times.

228 We used the package BioGeoBEARS (Matzke 2013b; Matzke 2013a) to estimate the ancestral 229 ranges of the dung beetles. The package implements some of the most popular models for 230 ancestral range estimation, DEC (Ree \& Smith 2008), DIVA (Ronquist 1997), and BayArea 231 (Landis et al. 2013), in the same framework, allowing them to easily be compared against each 232 other to test different biogeographical hypotheses. While the DEC model is a maximum 233 likelihood implementation just as originally implemented in Lagrange, the DIVA model was 234 originally implemented using parsimony, and in BioGeoBEARS the processes DIVA assumes are 235 modeled under maximum likelihood. Similarly, BayArea was originally implemented as 236 Bayesian, and is represented in BioGeoBEARS as a maximum likelihood interpretation of the 237 same. Thus, these two models should be referred to as DIVALIKE and BAYAREALIKE 238 respectively.

239 A popular feature of BioGeoBEARS is the addition of "jump-dispersal" to any of these models. 240 By adding the additional jump parameter (“+ $\mathrm{j}$ ”), one allows for founder events in the model, 241 meaning that at a speciation event, one descending lineage stays in the ancestral range, while the 242 other descendant jumps to a new area (Matzke 2014). However, there has recently been some 243 debate regarding the validity of the $+\mathrm{j}$ models (Ree \& Sanmartín 2018; Klaus \& Matzke 2019), 244 and this type of cladogenetic event is believed to be more important in island systems than in 245 non-island clades (Matzke 2013b). For those reasons, we decided not to employ the j parameter.

246 However, since the dispersal multiplier matrices defined above are somewhat arbitrary, we do 247 pair them with a parameter (w) that scales the matrix and that can be optimized as well, 248 constituting the $+\mathrm{w}$ models (Dupin et al. 2017). The parameter $\mathrm{w}$ is used to exponentiate the 249 dispersal multiplier before it is multiplied by the dispersal rate and is 1 by default. Thus, if the 250 multipliers play an important role in the biogeographical history of the group, w is likely to be 251 estimated to be larger than 1, whereas it should be estimated to be lower than 1 if the dispersal 252 matrix does not add much to explain the patterns. While this does not allow to modulate the 
relative strengths of the different multipliers, it seems reasonable to expect that w would be

254 estimated to downweigh the importance of a grossly unrealistic set of multipliers.

255 We employed each of the three base models (DEC, DIVALIKE, BAYAREALIKE) in four

256 different ways: 1) as a basic model (estimating d and e), 2) with the non-stratified manual

257 dispersal multiplier matrix and estimated w parameter, 3) as a time stratified model, and 4) as a

258 time stratified model with a manual dispersal multiplier matrix for each time slice, and estimated

259 w parameter. In all those analyses, we constrained the maximal range any lineage can occupy to

2603 , as none of the extant species occupy more than 3 areas. To account for the branch support

261 issues, we ran all these models both on the trees with old and young calibrations, as well as the

262 ten bootstrap trees each.

263 Finally, preliminary analyses produced curious results, particularly in the time stratified model,

264 where lineages within clades that where entirely present in one area (e.g. Madagascar) would

265 commonly disperse to a neighboring area (e.g. Africa) right after a speciation event, only to

266 return to the ancestral area again. It was presumed that clades in which every species inhabited

267 the same two areas (e.g. the Americas) would be responsible for this, as models as DEC do not

268 include the required scenario (cladogenesis in widespread taxa where both daughters inherit

269 widespread range). Thus, such cases required the above pattern of one daughter losing and re-

270 gaining the widespread range, thereby inflating the inferred dispersal rate and forcing other

271 lineages to do the same. We therefore created test data sets where we identified the area in which

272 species most commonly co-occurred (the Americas), or the two pairs of most co-inhabited areas

273 (the Americas and Eurasia), and coded those as one, thus getting a 6-area and 5-area dataset to be 274 analyzed separately.

\section{Diversification Analysis}

276 We tested two sets of biogeography-related hypotheses: whether areas with larger mammals and

277 more diverse droppings are associated with higher diversification rates of dung beetles, and

278 whether diversification rates were raised when dung beetles gained access to new habitats,

279 dispersing from Gondwana to Madagascar or Laurasia. The former hypothesis was derived from

280 Davis and Scholtz (2001); (also elaborated in Scholtz, Davis \& Kryger 2009). They classify 
mammalian dung into four types based on size and physico-chemical characteristics: 1) small dry pellets from small to medium herbivores, 2) small odiferous droppings from omni- or carnivores, 3) large, dry, course-fibered droppings from large non-ruminant herbivores, and 4) large, moist, fine-fibered pads from large ruminants. The number of those types of dung available, as well as the (fairly correlated) body size of mammals was tallied for different biogeographical regions, and shown to relate to aspects of dung beetle diversity (Davis \& Scholtz 2001; Scholtz, Davis \& Kryger 2009). 2011) or GeoHiSSE (Beaulieu \& O'Meara 2016; Caetano, O'Meara \& Beaulieu 2018) only test diversification between two areas (and three ranges: endemic to one or the other area, or widespread), making explicitly testing hypotheses involving more areas (not to speak of all seven) impossible. However, in the case of only three areas, testing different combinations of two against each other can still yield relevant insights. To this end, we re-coded the distribution data from above to merge occurrences 1) of areas with large mammals and diverse droppings

295 (Afro-Eurasia: Africa, Europe, and Asia), of medium sized mammals and less diverse droppings

296 (North and South America), and those of those with small mammals and the least diverse

297 droppings (East Gondwanan Fragments: Oceania and Madagascar).; and 2) those of the areas

298 formerly making up Gondwana (South America, Africa, and Oceania), those of former Laurasia

299 (North America, Europe, and Asia), while keeping Madagascar as an area of its own. We then

300 formatted these two data sets to suit the different GeoSSE tests: a set where we join the areas

301 with medium sized mammals and intermediate droppings-diversity with the areas of large

302 mammals and diverse droppings, and one where we join them with the small mammal and low

303 droppings-diversity instead. Another set of where we join Madagascar with Gondwana, where

304 we join it with Laurasia, and where we leave it as an area separate from the rest.

305 For each of the resulting five data sets (and for both the young and old tree respectively), we 306 inferred maximum likelihood estimates with GeoSSE, under a set of different model constraints.

307 The constraints used were combinations of equal speciation between areas, equal extinction 308 between areas, equal dispersal rates between areas, and variation where speciation was set to 309 zero in one area and forced to be equal in the other and widespread lineages, and vice versa. The 
310 full and constrained models were then compared using likelihood ratio tests and their $\Delta$ AIC

311 score. The best models for each combination of data set and tree were subsequently used to get

312 posterior distributions of the parameter estimates using MCMC, with an exponential prior related

313 to the Kendall-Moran estimate for net diversification rate (Kendall 1949; Moran 1951). A short

314 preliminary chain of 100 generations was run and the distances between the 5\% and 95\%

315 quantiles for each parameter were used to set the tuning parameter $\mathrm{w}$ for the slice sampler. Then,

316 each dataset was run for 20,000 generations. Convergence was assessed by the convergence

317 parameter of the function, by visual inspection of the log likelihood trace, and calculating

318 effective sample size using effectiveSize from the R package coda (Plummer et al. 2004). We

319 then compared the $95 \%$ quantiles of the posterior distribution for all estimated parameters to see

320 whether they overlap.

\section{Results}

\section{Phylogeny and Divergence Times}

323 Out of 122 genera represented in this phylogeny, 33 were monophyletic, 28 were non-

324 monophyletic, and 61 were monotypic (Table S2). When considering the bootstrap trees, 14

325 genera were consistently monophyletic, 22 consistently non-monophyletic, whereas the

326 remaining 25 varied between trees. On the tribal level, we recovered Eucraniini, Ateuchini,

327 Eurysterniini, Gymnopleurini, and Sisyphini as monophyletic (Table S3). Of these, only the last

328 three consistently so, with Onitini being monophyletic in some bootstrap replicates. Upon closer

329 inspection of the reasons for each tribe's non-monophyly (Table 1), we see that at least part of it

330 results from taxonomic issues. For Scarabaeini, Phanaeini, and Onitini, non-monophyly is due to

331 a few incertae sedis taxa, most of which monotypic. Oniticellini and Onthophagini have similar

332 issues where one intruder of the former is a member of the latter, but also the whole of

333 Oniticellini is nested within Onthophagini. Dichotomiini, Deltochilini and Canthonini are

334 scattered in clumps across the tree, with the latter two intermingling a lot, while Coprini come

335 out in three separate clades.

336 The estimated ages of the calibrated nodes for both the young and old calibration are given in

337 Table 2. It is apparent that under both calibration schemes, the crown age of the Scarabaeinae has 
338 hit its constrained maximum age, while the stem ages of the constrained nodes are not reaching

339 their maximum constraints but are often meeting or exceeding the minimum age constraint of the

340 subfamily's crown. The bootstrap branch support values can be seen in Figure 1.

\section{$341 \quad$ Ancestral Range Estimation}

342 For all analyses of the 7-area data set on the young and old maximum likelihood trees and their

343 respective sets of 10 bootstrap trees, the analyses recovered the unstratified DEC model with

344 manual dispersal multipliers $(\mathrm{DEC}+\mathrm{w})$ as the best-fitting model. In all trees, $\mathrm{w}-$ the exponent for

345 the dispersal multipliers - was estimated to be larger than 1 (1.71-2.83), indicating its weight in

346 the dispersal process being higher than the initial dispersal matrix suggested. The estimated

347 dispersal and extirpation rates vary between the trees but are comparable and at the very least in

348 the same order of magnitude. For the 6-area and 5-area datasets, which model was inferred to fit

349 best varied widely among the different trees.

350 The ancestral range of the whole subfamily was estimated to be Africa, Oceania, and South

351 America for both the young and old tree. However, in the alternative trees based on bootstrap

352 replicates, the estimated ancestral range could include Madagascar instead of South America or

353 instead of Oceania, or could just include Africa and Oceania (Table S6). Interestingly,

354 reconstructions with root states other than Africa, Oceania, and South America tended to be more

355 ambiguous. Overall, the estimated ancestral ranges seemed to suggest that numerous clades

356 mostly stay in the same areas (particularly Africa, Oceania, and Madagascar), with some more

357 dispersal within the Americas and Eurasia, as well as within the clade comprising the

358 Onthophagini and Oniticellini (Figure S1).

\section{Diversification Analyses}

360 The best fitting models for each data set and tree, according to likelihood ratio tests and $\triangle$ AIC

361 scores, are given in Table 3. The MCMC analyses converged and yielded reasonably high

362 effective sampling sizes with no value below 295. The 95\% quantiles of the posterior

363 distributions for each parameter estimate is given in Table 4. 
364 Regardless of whether the areas with medium sized mammals and intermediate diversity in

365 droppings were joined with the areas of large or small mammals, there was no significant

366 difference between them in terms of diversification rates (if the best model did not constrain

367 them; Figure 2, Figure 3). When the areas of medium and small mammals are joined, the

368 analysis attributes any difference in diversity between them to higher dispersal out of Afro-

369 Eurasia into the other areas.

370 Despite some differences in which model fitted the Gondwanan origin data best, the results

371 between the old tree (Figure 4) and the young tree (Figure 5) are largely consistent. They show

372 that lineages in Gondwana have a significantly lower speciation rate than lineages outside of it,

373 while lineages in Laurasia disperse into the other areas at a higher rate than vice-versa, while

374 there are no significant differences in either diversification nor dispersal between Madagascar

375 and the other areas.

\section{Discussion}

\section{Phylogeny and Taxonomy}

378 With 541 represented in-group species, this is to date the most inclusive dated species-level

379 molecular phylogeny of Scarabaeinae. Most previously inferred phylogenies of the group were

380 either constrained to specific sub-clades or regions (e.g. Davis \& Scholtz 2001; Wirta, Orsini \&

381 Hanski 2008; Sole \& Scholtz 2010; Wirta et al. 2010; Mlambo, Sole \& Scholtz 2015;

382 Breeschoten et al. 2016; Gunter et al. 2018), or part of a larger phylogeny where the main focus

383 accordingly was not or not only on dung beetles (Ahrens, Schwarzer \& Vogler 2014; Kim \&

384 Farrell 2015; Gunter et al. 2016; Toussaint et al. 2017). A recent large un-dated phylogeny by

385 Tarasov and Dimitrov (2016) based on 8 gene regions had a similar amount of terminals (547

386 with outgroup), though it constitutes a smaller sample of actual species diversity, as many

387 species were represented by multiple accessions and many were not determined to species level.

388 The levels of generic and tribal monophyly in this new phylogeny (Table S2, Table S3) and the

389 causes of it (Table 1) would suggest a reasonable level of agreement between this tree and

390 current taxonomy. The lack of support for many groupings within the tree (Figure 1), particularly

391 in the backbone, is cause for concern, as it not only suggests shortcomings in the inferred tree, 
392 but also casts doubt upon the reliability of analyses results derived from that tree. Other attempts

393 at phylogenies of the overall Scarabaeinae were plagued with similar patterns of low branch

394 support (Tarasov \& Dimitrov 2016), which suggests a general issue in the study of this group.

395 Molecular phylogenies have challenged the traditional classification, particularly the tribal

396 monophyly of Canthonini and Dichotomiini (Monaghan et al. 2007), as well as Coprini,

397 Onthophagini and Oniticellini, while the monophyly of the remaining tribes still seems supported

398 (Scholtz, Davis \& Kryger 2009). Tarasov and Dimitrov (2016) note how their own results are

399 consistent with those of previous phylogenetic studies of Scarabaeinae (Ocampo \& Hawks 2006;

400 Monaghan et al. 2007; Vaz-de-Mello 2007; Wirta, Orsini \& Hanski 2008; Sole \& Scholtz 2010;

401 Wirta et al. 2010; Mlambo, Sole \& Scholtz 2014; Gunter et al. 2016), as well as with a large

402 phylogeny based on morphology (Tarasov \& Génier 2015). They furthermore observed that the

403 studies to date tend to resolve old nodes and more recent nodes, but not intermediate ones, and

404 that the same set of problematic tribes mentioned above are consistently not monophyletic. All of

405 this seems to be reflected in our results as well, particularly when considering the extent of

406 monophyly problems (Table 1). Using the suggested new classification by Tarasov and Dimitrov

407 (2016) does not yield much improvement. While Eucraniini and Eurysternini are strictly

408 monophyletic in both, monophyly gained through reclassification in Dichotomiini, Canthonini,

409 and Scarabaeini is offset by the loss of it in Ateuchini, Gymnopleurini, and Sisyphini. Both

410 classifications show similar consistency across the set of bootstrap trees.

\section{Ancestral Range Estimation and the Origin of Scarabaeinae}

412 The two main hypotheses regarding where dung beetles originated are an origin in Gondwana

413 followed by vicariance events after the breakup of the supercontinent (Hanski \& Cambefort

414 1991; Davis \& Scholtz 2001; Davis, Scholtz \& Philips 2002), and an origin in Africa and

415 subsequent dispersal out of it (Sole \& Scholtz 2010). One major point of conflict between those

416 two ideas was the age of Scarabaeinae: Gondwanan vicariance would necessitate the group to be

417 of Mesozoic, rather than Cenozoic origin, as they would have to exist and be widespread enough

418 before the continental breakup (110ma according to Sanmartin and Ronquist (2004), 93ma

419 according to Scotese (1993)) in order for vicariance events to be plausible. 
420 To answer the question of biogeographic origin in absence of an appropriate phylogeny, some

421 workers relied on classification (Hanski \& Cambefort 1991; Davis \& Scholtz 2001), considering

422 widespread tribes to be ancient and predating the Gondwana-breakup, in turn giving rise to

423 younger, less widespread tribes. Later attempts combined the relative age of phylogenies

424 (Monaghan et al. 2007; Wirta, Orsini \& Hanski 2008) with fast and slow rates of molecular

425 sequence divergence in insects to get maximal and minimal divergence time estimates (Scholtz,

426 Davis \& Kryger 2009), concluding that even the slowest known divergence rates would not

427 support the idea of a pre-Gondwanan-breakup origin of dung beetles. Sole and Scholtz (2010)

428 subsequently used a time calibrated phylogeny of the African representatives of Canthonini and

429 Dicotomiini to address the question, finding the divergence times between dung beetles and their

430 outgroup, and of the crown of dung beetles to be considerably younger than the breakup of

431 Gondwana (56ma and 40ma respectively), thus further supporting the later out-of-Africa

432 scenario.

433 As for the divergence times inferred in this study (Table 2), the older age of 131.6ma would

434 place the origin of dung beetles well before the complete breakup of Gondwana, whereas the

435 younger estimate of $98.1 \mathrm{ma}$ appears ambiguous, depending on when the actual separation of

436 Gondwana was completed, and depending on the accuracy of this age estimate. In either case

437 however, the inference of older origins, similar to other recent estimates that considered more

438 than just a subset of Scarabaeinae (Ahrens, Schwarzer \& Vogler 2014; Gunter et al. 2016),

439 makes a Gondwanan origin and thus the potential for vicariance after its breakup seem like a

440 plausible option again.

441 The reconstruction of what is essentially Gondwana as the ancestral range at the crown of our

442 phylogenies seems to further support the idea of Gondwanan-vicariance. However, the DEC

443 model is known to have a bias towards widespread ancestors (Clark et al. 2008; Ree \& Smith

444 2008; Buerki et al. 2011; Matzke 2014), even if not as strongly as DIVA (Kodandaramaiah

445 2010). Therefore, since we constrained the number of areas a lineage can maximally inhabit to

446 three, the inference of those three areas as the origin could possibly be an artefact. With regards

447 to the branch support issues, it would appear that the consistency with which the same model

448 was preferred across all trees using the 7-area dataset, and the relative stability of the inferred 
origin to be Gondwana, or parts thereof (Table S6), could be seen as a sign that the result is robust enough. However, the wildly varying best supported model under the reduced area

451 datasets (6 and 5 areas) is cause for concern. It could be argued, that leaving those pairs or areas

452 separate (North and South America, Europe and Asia respectively), might lead to a distribution

453 of areas across clades that is not broken up when they are rearranged in the bootstrap trees, thus

454 implying the same dispersal mechanisms. On the contrary, lumping them could lead to single-

455 distribution clades being broken up, thus changing the number of implied dispersal and

456 vicariance events. However, this is rather speculative and requires further investigation. Finally,

457 while the high estimates for w suggest that the specified dispersal multipliers are a relevant

458 improvement of the model overall, this does not guarantee that they are an accurate

459 representation of dung beetle dispersal probabilities at the given times. While they might capture

460 some large-scale dispersal constraints, the relative magnitude of the dispersal multipliers

461 between specific continents could still be inaccurate, e.g. because of the way the barriers were

462 specified and the values they were assigned. Sensitivity tests, or even adding an approach using 463 actual distance, could help to inform us about this.

464 In any case, given the branch support issues, we would refrain from a too detailed interpretation 465 of the ranges reconstructed at internal nodes. However, it is notable that the reconstruction 466 suggests that many clades can be found which seem to be predominantly confined to one (or 467 few) areas, particularly to Oceania, Madagascar, and Africa, with some more dispersal in 468 American or Eurasian clades. An exception seems to be the clade comprising Onthophagini and 469 Oniticellini, which seems to have much more area changes. This could indicate that the

470 Onthophagini and Oniticellini are different from the remaining dung beetles in their

471 biogeographic history and maybe their dispersal abilities. It could however also just reflect a lack 472 of sampling in that clade.

\section{Diversification Analyses}

474 The GeoSSE results for the hypothesis on whether mammal size and available dung-diversity in 475 different biogeographical areas affected the diversification rates of Scarabaeinae seem to suggest 476 that this is not the case. The increased dispersal from Afro-Eurasia into the other regions is 477 certainly interesting and could reflect different plausible dispersal events. But given that the test 
was not set up to address these alternatives, we would suggest exercising care not to overinterpret this pattern. When Davis and Scholtz (2001) reported on the patterns among mammals, the diversity of their droppings, and dung beetle diversity in different areas of the world, they noted that it was particularly related to tribal diversity (and generic diversity within tribes) in those areas, but less correlated to genus or species diversity. They interpret this as a sign that the influence of these patterns in mammal body size and droppings on dung beetle diversification happened earlier in their evolutionary history, around the time when the tribes split. While the idea that mammal dung availability could have been a crucial influence on beetle diversification in the past appears very sensible, it would seem that the arguments presented in this particular case are problematic. Firstly, it relates an extant pattern in mammals to past effects in beetles assuming that the distribution of mammals and their droppings across the world was comparable between then and now. However, those extant patterns were almost certainly not constant over the timespan of dung beetle diversification, with the most recent event that changed those patterns already being the Late Quaternary megafaunal extinctions (Stuart 2015).

493 Gunter et al. 2016), the ages of many tribes may either be older than the rise of mammal

494 diversity, or would at least coincide with a time when mammal diversity would not be expected

495 to compare well to the extant one. Finally, considering the fact that the pattern does not correlate 496 well with species level diversity, the method we employed might also be suboptimal to test the 497 implied scenario of past influence, and an approach that allows the influence of mammal size and 498 droppings to be constrained to particular time-intervals might be more suitable.

499 The result of the Gondwanan origin GeoSSE analysis might initially seem surprising, as a large

500 portion of Scarabaeinae species diversity is found in areas that were formerly Gondwana

501 (Scholtz, Davis \& Kryger 2009) and the former-Gondwanan lineages were not underrepresented 502 in comparison to the others (Gondwana: 320 taxa, Laurasia: 143 taxa, Madagascar: 114 taxa).

503 But considering the possible Gondwanan origin of the whole group, and the perceived inertia of 504 clades (diversifying in an area rather than dispersing more), one might suggest that the larger 505 absolute number of species in former Gondwanaland results from diversifying at a lower rate but 506 over longer timespans than the on average probably younger Laurasian or Malagasy lineages.

507 This would also explain the lack of rate difference between the latter and Laurasia and 
508 Gondwana combined. The higher dispersal out of Laurasia was not expected, assuming the

509 general direction of dung beetle dispersal was outward from Gondwana. But in the light of

510 higher dispersal outside of Gondwana, this could reflect the dispersal of few lineages out of

511 Gondwana, where they diversified, and subsequently a few of those Laurasian taxa returned to

512 former Gondwana (e.g. in the case of taxa which returned from North America to South America

513 after closing of the isthmus). The lack of difference in dispersal rate between Madagascar and the

514 rest is plausible as well, knowing that most Malagasy dung beetles are part of one of few clades

515 that entered Madagascar and diversified there, with very few dispersals back (Miraldo et al.

516 2011; Sole et al. 2011). This is also reflected by the fact that the inferred rate between

517 Madagascar and the rest is comparatively low (Table 4). All in all, those results would support

518 the hypothesis that access to new areas was associated with a rise of diversification rates in dung

519 beetles. However, more fine-scale analyses are needed to confirm the implied scenarios behind

520 this. Also, while overall sampling frequency in this phylogeny was considered in this analysis, it

521 cannot be ruled out that some of these results are artefacts of uneven sampling between groups

522 within the subfamily. Until an even more complete tree of Scarabaeinae is available, finding

523 ways to correct for such sampling biases would be advisable.

\section{Acknowledgements}

525 We would like to express our thankfulness for helpful discussions and comments at various 526 stages of this project to Kimberly Sheldon, Nicole Gunter, Sergei Tarasov, Nick Matzke, Jim

527 Fordyce, Colin Sumrall, Dave Bapst, Michelle Lawing, Jeremy Beaulieu, Luna Sanchez-Reyes,

528 Veronica Brown, Marisol Sanchez, Todd Pierson, Hailee Korotkin, Claire Winfrey, Jess Dreyer, 529 and Maggie Mamantov.

530 Finally, we thank the Society of Systematic Biologists and the Systematics Association for their 531 financial support towards this project. 


\section{References}

534

535

536

537

538

539

540

541

542

543

544

545

546

547

548

549

550

551

552

553

554

555

556

557

558

559

560

561

562

563

564

565

566

567

568

Aberer, A.J., Krompass, D. \& Stamatakis, A. (2013) Pruning Rogue Taxa Improves Phylogenetic Accuracy: An Efficient Algorithm and Webservice. Systematic Biology, 62, 162-166.

Ahrens, D., Schwarzer, J. \& Vogler, A.P. (2014) The evolution of scarab beetles tracks the sequential rise of angiosperms and mammals. Proceedings of the Royal Society BBiological Sciences, 281.

Altschul, S.F., Madden, T.L., Schaffer, A.A., Zhang, J.H., Zhang, Z., Miller, W. \& Lipman, D.J. (1997) Gapped BLAST and PSI-BLAST: a new generation of protein database search programs. Nucleic Acids Research, 25, 3389-3402.

Beaulieu, J.M. \& O'Meara, B.C. (2016) Detecting Hidden Diversification Shifts in Models of Trait-Dependent Speciation and Extinction. Systematic Biology, 65, 583-601.

Blackmon, H. \& Adams, R. (2015) EvobiR: tools for comparative analyses and teaching evolutionary biology.

Breeschoten, T., Doorenweerd, C., Tarasov, S. \& Vogler, A.P. (2016) Phylogenetics and biogeography of the dung beetle genus Onthophagus inferred from mitochondrial genomes. Molecular Phylogenetics and Evolution, 105, 86-95.

Buerki, S., Forest, F., Alvarez, N., Nylander, J.A.A., Arrigo, N. \& Sanmartin, I. (2011) An evaluation of new parsimony-based versus parametric inference methods in biogeography: a case study using the globally distributed plant family Sapindaceae. Journal of Biogeography, 38, 531-550.

Caetano, D.S., O'Meara, B.C. \& Beaulieu, J.M. (2018) Hidden state models improve statedependent diversification approaches, including biogeographical models. Evolution, 72, 2308-2324.

Castresana, J. (2000) Selection of conserved blocks from multiple alignments for their use in phylogenetic analysis. Molecular Biology and Evolution, 17, 540-552.

Chamberlain, S., Ram, K., Barve, V. \& Mcglinn, D. (2016) rgbif: Interface to the Global "Biodiversity" Information Facility "API". R package version 0.9. 8.

Chamberlain, S.A. \& Boettiger, C. (2017) R Python, and Ruby clients for GBIF species occurrence data. PeerJ Preprints.

Chamberlain, S.A. \& Szocs, E. (2013) taxize: taxonomic search and retrieval in R. F1000Research, 2, 191-191.

Charif, D., Thioulouse, J., Lobry, J.R. \& Perriere, G. (2005) Online synonymous codon usage analyses with the ade4 and seqinR packages. Bioinformatics, 21, 545-547.

Clark, J.R., Ree, R.H., Alfaro, M.E., King, M.G., Wagner, W.L. \& Roalson, E.H. (2008) A comparative study in ancestral range reconstruction methods: retracing the uncertain histories of insular lineages. Systematic Biology, 57, 693-707. 
Davis, A.L., Scholtz, C.H. \& Sole, C.L. (2016) Biogeographical and co-evolutionary origins of scarabaeine dung beetles: Mesozoic vicariance versus Cenozoic dispersal and dinosaur versus mammal dung. Biological Journal of the Linnean Society, 120, 258-273.

Davis, A.L.V. \& Scholtz, C.H. (2001) Historical vs. ecological factors influencing global patterns of scarabaeine dung beetle diversity. Diversity and Distributions, 7, 161-174.

Davis, A.L.V., Scholtz, C.H. \& Philips, T.K. (2002) Historical biogeography of scarabaeine dung beetles. Journal of Biogeography, 29, 1217-1256.

Duchene, S., Molak, M. \& Ho, S.Y.W. (2014) ClockstaR: choosing the number of relaxed-clock models in molecular phylogenetic analysis. Bioinformatics, 30, 1017-1019.

Dupin, J., Matzke, N.J., Särkinen, T., Knapp, S., Olmstead, R.G., Bohs, L. \& Smith, S.D. (2017) Bayesian estimation of the global biogeographical history of the Solanaceae. Journal of Biogeography, 44, 887-899.

Goldberg, E.E., Lancaster, L.T. \& Ree, R.H. (2011) Phylogenetic Inference of Reciprocal Effects between Geographic Range Evolution and Diversification. Systematic Biology, 60, 451465.

Guindon, S., Dufayard, J.F., Lefort, V., Anisimova, M., Hordijk, W. \& Gascuel, O. (2010) New Algorithms and Methods to Estimate Maximum-Likelihood Phylogenies: Assessing the Performance of PhyML 3.0. Systematic Biology, 59, 307-321.

Gunter, N.L., Monteith, G.B., Cameron, S.L. \& Weir, T.A. (2018) Evidence from Australian mesic zone dung beetles supports their Gondwanan origin and Mesozoic diversification of the Scarabaeinae. Insect Systematics \& Evolution, 1, 1-27.

Gunter, N.L., Weir, T.A., Slipinksi, A., Bocak, L. \& Cameron, S.L. (2016) If Dung Beetles (Scarabaeidae: Scarabaeinae) Arose in Association with Dinosaurs, Did They Also Suffer a Mass Co-Extinction at the K-Pg Boundary? Plos One, 11.

Hanski, I. \& Cambefort, Y. (1991) Dung beetle ecology. Dung beetle ecology., i-xii, 1-481.

Hosner, P.A., Braun, E.L. \& Kimball, R.T. (2015) Land connectivity changes and global cooling shaped the colonization history and diversification of New World quail (Aves: Galliformes: Odontophoridae). Journal of Biogeography, 42, 1883-1895.

Kendall, D.G. (1949) Stochastic processes and population growth. Journal of the Royal Statistical Society. Series B (Methodological), 11, 230-282.

Kim, S.I. \& Farrell, B.D. (2015) Phylogeny of world stag beetles (Coleoptera: Lucanidae) reveals a Gondwanan origin of Darwin's stag beetle. Molecular Phylogenetics and Evolution, 86, 35-48.

Klaus, K.V. \& Matzke, N.J. (2019) Statistical Comparison of Trait-dependent Biogeographical Models indicates that Podocarpaceae Dispersal is influenced by both Seed Cone Traits and Geographical Distance. Systematic Biology.

Kodandaramaiah, U. (2010) Use of dispersal-vicariance analysis in biogeography-a critique. Journal of Biogeography, 37, 3-11. 
Krell, F.-T. (2000) The fossil record of Mesozoic and Tertiary Scarabaeoidea (Coleoptera: Polyphaga). Invertebrate Systematics, 14, 871-905.

Krell, F.-T. (2006) Fossil record and evolution of Scarabaeoidea (Coleoptera: Polyphaga). The Coleopterists Bulletin, 60, 120-143.

Landis, M.J., Matzke, N.J., Moore, B.R. \& Huelsenbeck, J.P. (2013) Bayesian Analysis of Biogeography when the Number of Areas is Large. Systematic Biology, 62, 789-804.

Lanfear, R., Calcott, B., Ho, S.Y.W. \& Guindon, S. (2012) PartitionFinder: Combined Selection of Partitioning Schemes and Substitution Models for Phylogenetic Analyses. Molecular Biology and Evolution, 29, 1695-1701.

Lanfear, R., Frandsen, P.B., Wright, A.M., Senfeld, T. \& Calcott, B. (2017) PartitionFinder 2: New Methods for Selecting Partitioned Models of Evolution for Molecular and Morphological Phylogenetic Analyses. Molecular Biology and Evolution, 34, 772-773.

Larsson, A. (2014) AliView: a fast and lightweight alignment viewer and editor for large datasets. Bioinformatics, 30, 3276-3278.

Losey, J.E. \& Vaughan, M. (2006) The economic value of ecological services provided by insects. Bioscience, 56, 311-323.

Matzke, N.J. (2013a) BioGeoBEARS: BioGeography with Bayesian (and likelihood) evolutionary analysis in R Scripts. $R$ package, version 0.2, 1, 2013.

Matzke, N.J. (2013b) Probabilistic Historical Biogeography: New Models for Founder-Event Speciation, Imperfect Detection, and Fossils Allow Improved Accuracy and ModelTesting. Frontiers of Biogeography, 5, 242-248.

Matzke, N.J. (2014) Model Selection in Historical Biogeography Reveals that Founder-Event Speciation Is a Crucial Process in Island Clades. Systematic Biology, 63, 951-970.

McKenna, D.D., Farrell, B.D., Caterino, M.S., Farnum, C.W., Hawks, D.C., Maddison, D.R., Seago, A.E., Short, A.E.Z., Newton, A.F. \& Thayer, M.K. (2015) Phylogeny and evolution of Staphyliniformia and Scarabaeiformia: forest litter as a stepping stone for diversification of nonphytophagous beetles. Systematic Entomology, 40, 35-60.

Miraldo, A., Hewitt, G.M., Paulo, O.S. \& Emerson, B.C. (2011) Phylogeography and demographic history of Lacerta lepida in the Iberian Peninsula: multiple refugia, range expansions and secondary contact zones. Bmc Evolutionary Biology, 11.

Miraldo, A., Wirta, H. \& Hanski, I. (2011) Origin and diversification of dung beetles in Madagascar. Insects, 2, 112-127.

Mlambo, S., Sole, C.L. \& Scholtz, C.H. (2014) Affinities of the Canthonini dung beetles of the Eastern Arc Mountains. Organisms Diversity \& Evolution, 14, 115-120.

Mlambo, S., Sole, C.L. \& Scholtz, C.H. (2015) A molecular phylogeny of the African Scarabaeinae (Coleoptera: Scarabaeidae). Arthropod Systematics \& Phylogeny, 73, 303321. 
Moczek, A. (2011) Evolution and development: onthophagus beetles and the evolutionary developmental genetics of innovation, allometry and plasticity. Ecology and evolution of dung beetles, 126-151.

Monaghan, M.T., Inward, D.J.G., Hunt, T. \& Vogler, A.P. (2007) A molecular phylogenetic analysis of the Scarabaeinae (dung beetles). Molecular Phylogenetics and Evolution, 45, 674-692.

Moran, P. (1951) Estimation methods for evolutive processes. Journal of the Royal Statistical Society: Series B (Methodological), 13, 141-146.

Nichols, E., Spector, S., Louzada, J., Larsen, T., Amequita, S., Favila, M.E. \& Scarabaeinae Res, N. (2008) Ecological functions and ecosystem services provided by Scarabaeinae dung beetles. Biological Conservation, 141, 1461-1474.

Ocampo, F.C. \& Hawks, D.C. (2006) Molecular phylogenetics and evolution of the food relocation behaviour of the dung beetle tribe Eucraniini (Coleoptera : Scarabaeidae : Scarabaeinae). Invertebrate Systematics, 20, 557-570.

Paradis, E., Claude, J. \& Strimmer, K. (2004) APE: Analyses of Phylogenetics and Evolution in R language. Bioinformatics, 20, 289-290.

Plummer, M., Best, N., Cowles, K. \& Vines, K. (2004) CODA: Output Analysis and Diagnostics for MCMC, R package version 0.13-3, 2008. CRAN: The Comprehensive R Archive Network.

R Development Core Team (2014) R: A language and environment for statistical computing. R Foundation for Statistical Computing, Vienna, Austria.

Ree, R.H. \& Sanmartín, I. (2018) Conceptual and statistical problems with the DEC+ J model of founder-event speciation and its comparison with DEC via model selection. Journal of Biogeography, 45, 741-749.

Ree, R.H. \& Smith, S.A. (2008) Maximum likelihood inference of geographic range evolution by dispersal, local extinction, and cladogenesis. Systematic Biology, 57, 4-14.

Reguero, M.A., Gelfo, J.N., López, G.M., Bond, M., Abello, A., Santillana, S.N. \& Marenssi, S.A. (2014) Final Gondwana breakup: the Paleogene South American native ungulates and the demise of the South America-Antarctica land connection. Global and Planetary Change, 123, 400-413.

Ronquist, F. (1997) Dispersal-vicariance analysis: A new approach to the quantification of historical biogeography. Systematic Biology, 46, 195-203.

Sanmartin, I. \& Ronquist, F. (2004) Southern hemisphere biogeography inferred by event-based models: plant versus animal patterns. Systematic Biology, $\mathbf{5 3}$.

Sayers, E.W., Cavanaugh, M., Clark, K., Ostell, J., Pruitt, K.D. \& Karsch-Mizrachi, I. (2019) GenBank. Nucleic Acids Research, 47, D94-D99.

Schöfl, G. (2016) reutils: Talk to the NCBI EUtils. R package, version 0.2.3.

Scholtz, C. \& Chown, S. (1995) The evolution of habitat use and diet in the Scarabaeoidea: a phylogenetic approach [pp. 355-374]. Biology, Phylogeny, and Classification of 
Coleoptera: Papers Celebrating the 80th Birthday of Roy A. Crowson. J. Pakaluk and SA Slipinski (eds.). Muzeum i Instytut Zoologii PAN, Warszawa, Poland.

Scholtz, C.H., Davis, A.L.V. \& Kryger, U. (2009) Evolutionary biology and conservation of dung beetles. Pensoft Sofia.

Schwery, O. \& O'Meara, B.C. (2016) MonoPhy: a simple R package to find and visualize monophyly issues. PeerJ Computer Science, 2, e56.

Scotese, C. (1993) Maps of generalized continental positions and orography produced by the palaeomap project, University of Texas, Arlington. Terrestrial ecosystems through time.

Seton, M., Müller, R., Zahirovic, S., Gaina, C., Torsvik, T., Shephard, G., Talsma, A., Gurnis, M., Turner, M. \& Maus, S. (2012) Global continental and ocean basin reconstructions since 200 Ma. Earth-Science Reviews, 113, 212-270.

Smith, S.A. \& O'Meara, B.C. (2012) treePL: divergence time estimation using penalized likelihood for large phylogenies. Bioinformatics, 28, 2689-2690.

Sole, C.L. \& Scholtz, C.H. (2010) Did dung beetles arise in Africa? A phylogenetic hypothesis based on five gene regions. Molecular Phylogenetics and Evolution, 56, 631-641.

Sole, C.L., Wirta, H., Forgie, S.A. \& Scholtz, C.H. (2011) Origin of Madagascan Scarabaeini dung beetles (Coleoptera: Scarabaeidae): dispersal from Africa. Insect Systematics \& Evolution, 42, 29-40.

Spector, S. (2006) Scarabaeine dung beetles (Coleoptera: Scarabaeidae: Scarabaeinae): an invertebrate focal taxon for biodiversity research and conservation. The Coleopterists Bulletin, 60, 71-83.

Stamatakis, A. (2014) RAxML version 8: a tool for phylogenetic analysis and post-analysis of large phylogenies. Bioinformatics, 30, 1312-1313.

Stuart, A.J. (2015) Late Quaternary megafaunal extinctions on the continents: a short review. Geological Journal, 50, 338-363.

Tarasov, S. \& Dimitrov, D. (2016) Multigene phylogenetic analysis redefines dung beetles relationships and classification (Coleoptera: Scarabaeidae: Scarabaeinae). Bmc Evolutionary Biology, 16.

Tarasov, S. \& Génier, F. (2015) Innovative Bayesian and parsimony phylogeny of dung beetles (Coleoptera, Scarabaeidae, Scarabaeinae) enhanced by ontology-based partitioning of morphological characters. Plos One, 10, e0116671.

Tarasov, S., Vaz-de-Mello, F.Z., Krell, F.T. \& Dimitrov, D. (2016) A review and phylogeny of Scarabaeine dung beetle fossils (Coleoptera: Scarabaeidae: Scarabaeinae), with the description of two Canthochilum species from Dominican amber. Peerj, 4.

Toussaint, E.F., Bloom, D. \& Short, A.E. (2017) Cretaceous West Gondwana vicariance shaped giant water scavenger beetle biogeography. Journal of Biogeography, 44, 1952-1965.

Toussaint, E.F.A., Seidel, M., Arriaga-Varela, E., Hajek, J., Kral, D., Sekerka, L., Short, A.E.Z. \& Fikacek, M. (2017) The peril of dating beetles. Systematic Entomology, 42, 1-10. 
721 Vaz-de-Mello, F. (2007) Revision taxonomica e analysis phylogenetico de la tribu Ateuchini.

722 Xalapa, Veracruz, Mexico: Instituto de Ecologia AC.

723 Wilkinson, S.P., Davy, S.K., Bunce, M. \& Stat, M. (2018) Taxonomic identification of

724 environmental DNA with informatic sequence classification trees.

725 Wirta, H., Orsini, L. \& Hanski, I. (2008) An old adaptive radiation of forest dung beetles in

726 Madagascar. Molecular Phylogenetics and Evolution, 47, 1076-1089.

727 Wirta, H., Viljanen, H., Orsini, L., Montreuil, O. \& Hanski, I. (2010) Three parallel radiations of

728 Canthonini dung beetles in Madagascar. Molecular Phylogenetics and Evolution, 57,

729 710-727.

730 


\section{Tables and Figures}

\section{Table 1 Tribal Monophyly-Issues Dung Beetles}

Monophyly status and reasons for non-monophyly for all tribes in the full matrix trees. Mon.=monophyly-status, \#Tips=number of taxa assigned to this tribe, $\Delta$ Tips=number of additional taxa in this clade (descendants of same MRCA), \#Intr=number of tribes among intruder taxa, Intruders=Genera or Tribes intruding (numbers in parentheses are numbers of tips, all taxa incertae sedis unless indicated otherwise), \#Outl.=number of taxon-members outside the main clade.

\begin{tabular}{|c|c|c|c|c|c|c|c|}
\hline Tribe & Mon. & \#Tips & $\Delta$ Tips & \#Intr. & Intruders & \#Outl. & Outliers \\
\hline Eucraniini & Yes & 8 & 0 & 0 & & NA & \\
\hline Ateuchini & Yes & 2 & 0 & 0 & & NA & \\
\hline Eurysternini & Yes & 6 & 0 & 0 & & NA & \\
\hline Gymnopleurini & Yes & 8 & 0 & 0 & & NA & \\
\hline Sisyphini & Yes & 6 & 0 & 0 & & NA & \\
\hline Scarabaeini & No & 37 & 1 & 1 & Neateuchus (1) & 0 & \\
\hline Phanaeini & No & 44 & 2 & 1 & $\begin{array}{l}\text { Diabroctis (1), } \\
\text { Dendropaemon (1) }\end{array}$ & 0 & \\
\hline Onitini & No & 7 & 2 & 1 & Cheironitis (2) & 0 & \\
\hline Oniticellini & No & 36 & 10 & 2 & $\begin{array}{l}\text { Tiniocellus }(2), \\
\text { Tragiscus }(1), \\
\text { Drepanocerus }(4), \\
\text { Cyptochirus }(1), \\
\text { Heterosyphus }(1), \\
\text { Proagoderus }(1, \\
\text { Onthophagini) }\end{array}$ & 0 & \\
\hline Onthophagini & No & 119 & 53 & 1 & $\begin{array}{l}\text { Hyalonthophagus (2), } \\
\text { Cleptocaccobius (1), } \\
\text { Euonthophagus (2), } \\
\text { Milichus (1) }\end{array}$ & 16 & $\begin{array}{l}\text { Onthophagus diabolicus } \\
\text { and } 15 \text { more. }\end{array}$ \\
\hline Deltochilini & No & 132 & 414 & 1 & Canthonini (2) & 112 & $\begin{array}{l}\text { Arachnodes emmae and } \\
111 \text { more. }\end{array}$ \\
\hline Canthonini & No & 52 & 494 & 1 & Deltochilini (7) & 25 & $\begin{array}{l}\text { Megathopa villosa and } \\
24 \text { more. }\end{array}$ \\
\hline Coprini & No & 23 & 501 & 1 & Paracopris (1) & 10 & $\begin{array}{l}\text { Coptodactyla storeyi and } \\
9 \text { more. }\end{array}$ \\
\hline Dichotomiini & No & 36 & 510 & 0 & & 24 & $\begin{array}{l}\text { Canthidium haroldi and } \\
23 \text { more. }\end{array}$ \\
\hline
\end{tabular}


bioRxiv preprint doi: https://doi.org/10.1101/2021.0126.428346; this version posted January 27,2021 . The copyright holder for this preprint (which was not certified by peer review) is the author/funder, who has granted bioRxiv a license to display the preprint in perpetuity. It is made available under aCC-BY-NC-ND 4.0 International license.

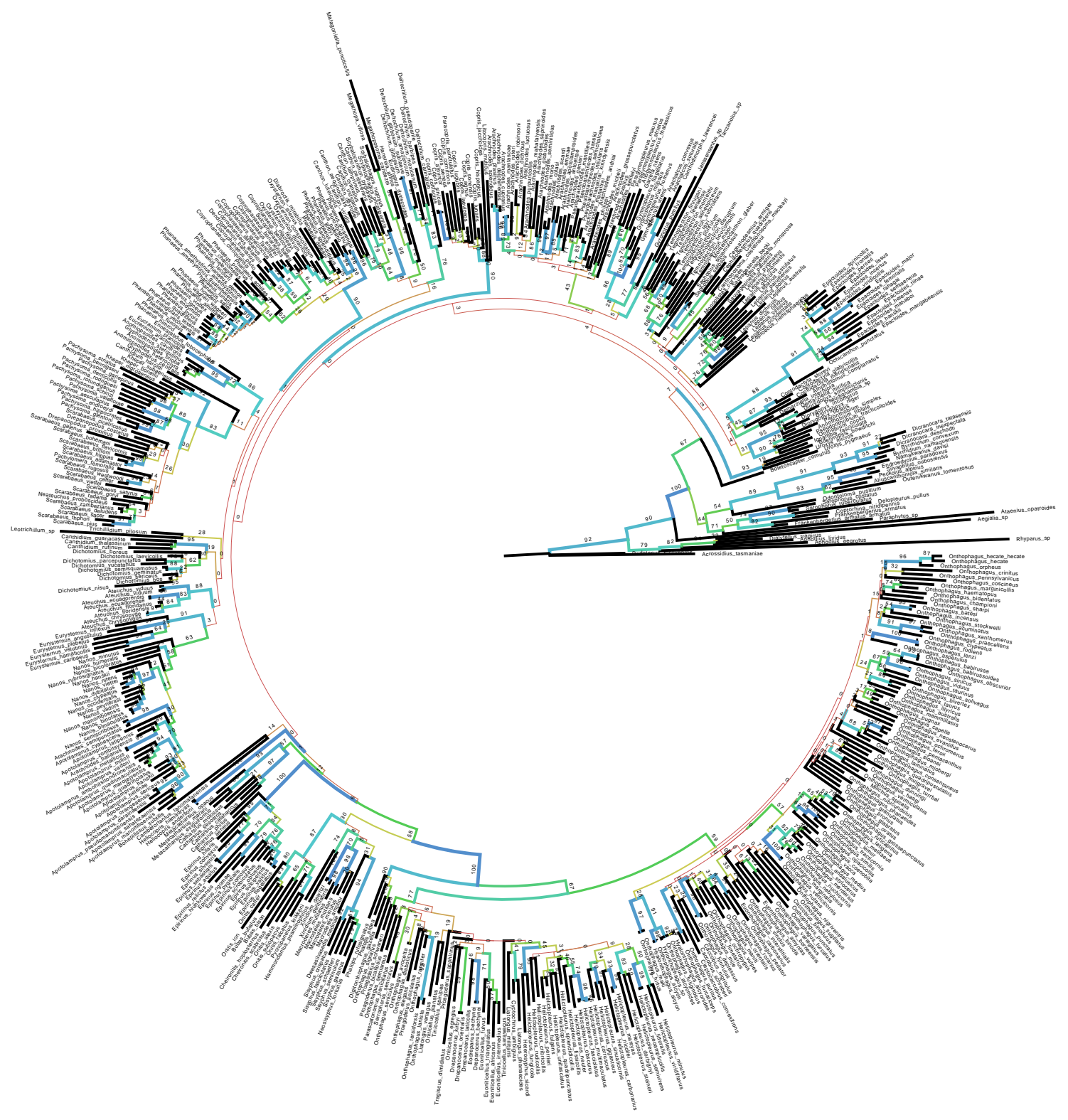

\section{Figure 1: Branch Support Dung Beetle Phylogeny.}

Bootstrap branch length support on the un-dated RAxML phylogeny. Colder colors indicating higher branch support, decreasing branch width with decreasing support (terminal branches are black). 


\section{Table 2 Node Calibrations and Estimated Ages.}

For each node age calibration, the corresponding clade, fossil, location on the branch (crown or stem) are given. For each calibration scheme ('young' vs. 'old'), the age constraints used and the estimated node ages on crown and stem, are indicated for each calibrated node, followed by the difference between the estimates.

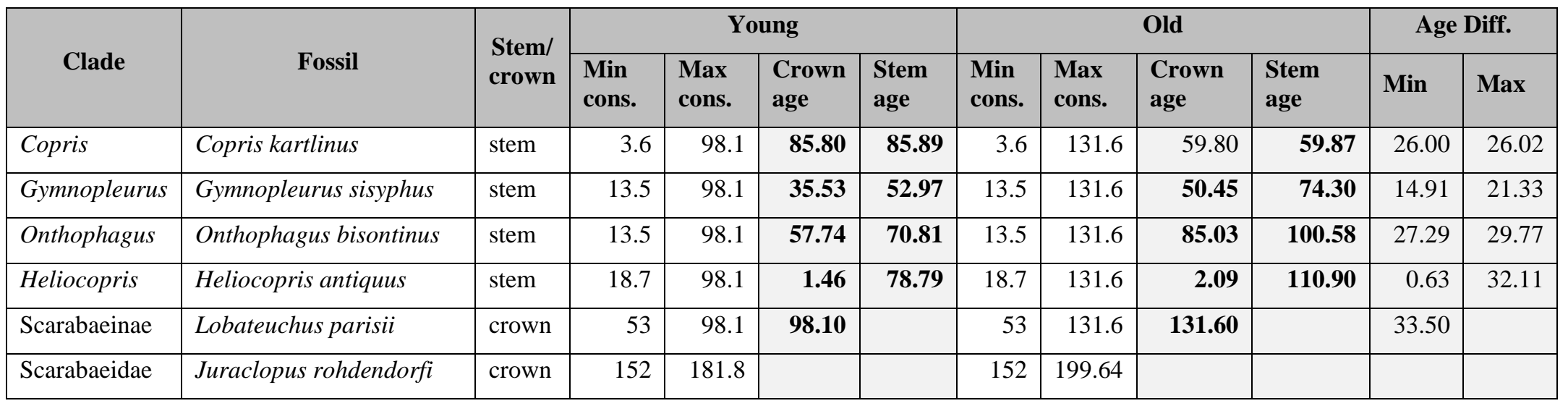




\section{Table 3 Best Fitting Models for Biogeographcal Diversification Hypotheses.}

Best fitting models of ML GeoSSE analyses for each data set and each tree, as determined by likelihood ratio tests and $\triangle \mathrm{AIC}$ scores. Models where lambda was constrained to be equal in both areas, also constrained lambda to be zero for widespread taxa.

\begin{tabular}{|l|l|l|}
\hline Tested Pairing & Young Tree & Old Tree \\
\hline Large Mammals vs. rest & $\begin{array}{l}\text { equal } \mathrm{mu}, \\
\text { equal dispersal }\end{array}$ & $\begin{array}{l}\text { equal mu, } \\
\text { equal dispersal }\end{array}$ \\
\hline Small Mammals vs. rest & $\begin{array}{l}\text { equal lambda, } \\
\text { equal mu }\end{array}$ & $\begin{array}{l}\text { equal lambda, } \\
\text { equal mu }\end{array}$ \\
\hline Gondwana vs. rest & equal mu & $\begin{array}{l}\text { equal mu, } \\
\text { equal dispersal }\end{array}$ \\
\hline Laurasia vs . rest & full model & $\begin{array}{l}\text { equal lambda, } \\
\text { equal mu }\end{array}$ \\
\hline Madagascar vs. rest & equal dispersal & $\begin{array}{l}\text { equal mu, } \\
\text { equal dispersal }\end{array}$ \\
\hline
\end{tabular}


bioRxiv preprint doi: https://doi.org/10.1101/2021.01.26.428346; this version posted January 27, 2021. The copyright holder for this preprint

(which was not certified by peer review) is the author/funder, who has granted bioRxiv a license to display the preprint in perpetuity. It is made available under aCC-BY-NC-ND 4.0 International license.

Table 4 Posterior Distribution of GeoSSE Rate Estimates.

95\% quantiles of posterior distributions for diversification and dispersal rates estimated under the best scoring model for each data set and each tree. $s=$ speciation rate, $x=e x t i n c t i o n$ rate, $r=$ net diversification rate $(s-x), d=$ dispersal rate.

\begin{tabular}{|c|c|c|c|c|c|c|c|c|c|c|c|c|}
\hline \multirow{2}{*}{ Pairings } & Quant. & sA & sB & SAB & $\mathbf{x A}$ & $\mathbf{x B}$ & $\mathbf{r A}$ & rB & rAB & dA & dB & Likelihood \\
\hline & \multicolumn{12}{|c|}{ Young Tree } \\
\hline \multirow{2}{*}{$\begin{array}{l}\text { Only Large } \\
\text { Mam. Vs. } \\
\text { rest }\end{array}$} & $2.50 \%$ & 0.0968 & 0.0942 & 0.0382 & & 0.0192 & 0.0636 & 0.0600 & 0.0382 & & 0.0008 & -2436.8114 \\
\hline & $97.50 \%$ & 0.1449 & 0.1437 & 3.9306 & & 0.0785 & 0.0803 & 0.0799 & 3.9306 & & 0.0021 & -2428.7662 \\
\hline \multirow{2}{*}{$\begin{array}{c}\text { Only Small } \\
\text { Mam. vs. } \\
\text { rest }\end{array}$} & $2.50 \%$ & & 0.1076 & & & 0.0342 & & 0.0613 & & 0.0002 & 0.0015 & -2436.8855 \\
\hline & $97.50 \%$ & & 0.1552 & & & 0.0922 & & 0.0756 & & 0.0014 & 0.0042 & -2431.4368 \\
\hline \multirow{2}{*}{$\begin{array}{c}\text { Madagascar } \\
\text { vs. rest }\end{array}$} & $2.50 \%$ & 0.1041 & 0.0930 & 0.1085 & 0.0006 & 0.0191 & 0.0770 & 0.0602 & 0.1085 & & 0.0003 & -2381.0849 \\
\hline & $97.50 \%$ & 0.2102 & 0.1423 & 8.0402 & 0.1276 & 0.0798 & 0.1158 & 0.0756 & 8.0402 & & 0.0010 & -2373.0650 \\
\hline \multirow{2}{*}{$\begin{array}{c}\text { Laurasia } \\
\text { vs . rest }\end{array}$} & $2.50 \%$ & 0.0819 & 0.0863 & 0.0016 & 0.0006 & 0.0160 & 0.0581 & 0.0528 & 0.0016 & 0.0223 & 0.0003 & -2619.1510 \\
\hline & $97.50 \%$ & 0.1308 & 0.1409 & 0.0651 & 0.0674 & 0.0857 & 0.0928 & 0.0724 & 0.0651 & 0.0577 & 0.0036 & -2610.9780 \\
\hline \multirow{2}{*}{$\begin{array}{c}\text { Gondwana } \\
\text { vs. rest }\end{array}$} & $2.50 \%$ & 0.0964 & 0.0683 & 0.0002 & & 0.0008 & 0.0863 & 0.0593 & 0.0002 & 0.0051 & 0.0028 & -2629.9069 \\
\hline & $97.50 \%$ & 0.1228 & 0.0924 & 0.0309 & & 0.0305 & 0.1054 & 0.0721 & 0.0309 & 0.0156 & 0.0056 & -2622.8756 \\
\hline Pairings & \multicolumn{12}{|c|}{ Old Tree } \\
\hline \multirow{2}{*}{$\begin{array}{l}\text { Only Large } \\
\text { Mam. vs. } \\
\text { rest }\end{array}$} & $2.50 \%$ & 0.0636 & 0.0619 & 0.0286 & & 0.0093 & 0.0448 & 0.0426 & 0.0286 & & 0.0005 & -2632.4797 \\
\hline & $97.50 \%$ & 0.0952 & 0.0942 & 1.5142 & & 0.0486 & 0.0560 & 0.0557 & 1.5142 & & 0.0013 & -2624.6484 \\
\hline \multirow{2}{*}{$\begin{array}{c}\text { Only Small } \\
\text { Mam. vs. } \\
\text { rest }\end{array}$} & $2.50 \%$ & & 0.0698 & & & 0.0183 & & 0.0435 & & 0.0001 & 0.0010 & -2633.0250 \\
\hline & $97.50 \%$ & & 0.0994 & & & 0.0546 & & 0.0530 & & 0.0009 & 0.0029 & -2627.6812 \\
\hline \multirow{2}{*}{$\begin{array}{c}\text { Madagascar } \\
\text { vs. rest }\end{array}$} & $2.50 \%$ & 0.0726 & 0.0575 & 0.0952 & & 0.0043 & 0.0558 & 0.0437 & 0.0952 & & 0.0002 & -2578.7214 \\
\hline & $97.50 \%$ & 0.1066 & 0.0887 & 6.9666 & & 0.0438 & 0.0753 & 0.0544 & 6.9666 & & 0.0007 & -2571.5387 \\
\hline \multirow{2}{*}{$\begin{array}{c}\text { Laurasia } \\
\text { vs . rest }\end{array}$} & $2.50 \%$ & & 0.0602 & & & 0.0103 & & 0.0394 & & 0.0137 & 0.0002 & -2810.4804 \\
\hline & $97.50 \%$ & & 0.0851 & & & 0.0443 & & 0.0513 & & 0.0327 & 0.0027 & -2805.3483 \\
\hline \multirow{2}{*}{$\begin{array}{c}\text { Gondwana } \\
\text { vs. rest }\end{array}$} & $2.50 \%$ & 0.0627 & 0.0477 & 0.0001 & & 0.0003 & 0.0580 & 0.0437 & 0.0001 & & 0.0028 & -2829.6036 \\
\hline & $97.50 \%$ & 0.0780 & 0.0611 & 0.0174 & & 0.0152 & 0.0702 & 0.0512 & 0.0174 & & 0.0045 & -2822.8190 \\
\hline
\end{tabular}



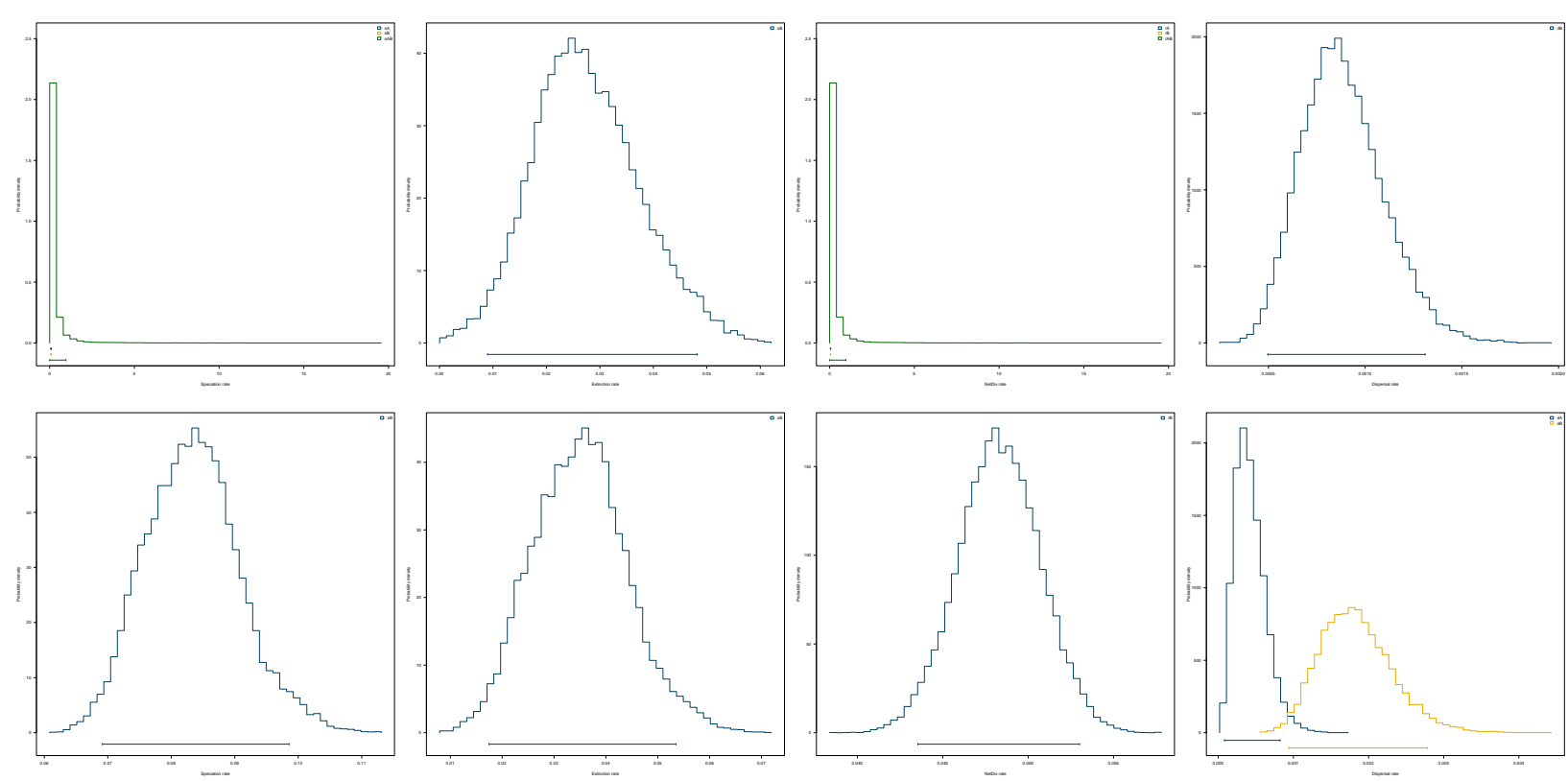

Figure 2: GeoSSE Results Dung Producers Old Tree.

Posterior distributions of area-dependent rates estimated by GeoSSE. Left to right: speciation rates, extinction rates, net diversification rates (speciation - extinction), dispersal rates. Top: rates in areas with large and medium sized mammals and high and intermediate droppingsdiversity (Afro-Eurasia and Americas, blue), and rates in areas with small sized mammals and low droppings-diversity (East Gondwanan Fragments, yellow). Bottom: rates in areas with large sized mammals and high droppings-diversity (Afro-Eurasia, yellow), and rates of areas with low and medium sized mammals and low and intermediate droppings-diversity (Americas and East Gondwanan Fragments, blue). Rates of widespread taxa are colored green; where only one rate was estimated, it is colored blue. Dispersal rates of an area reflect dispersal out of said area. 

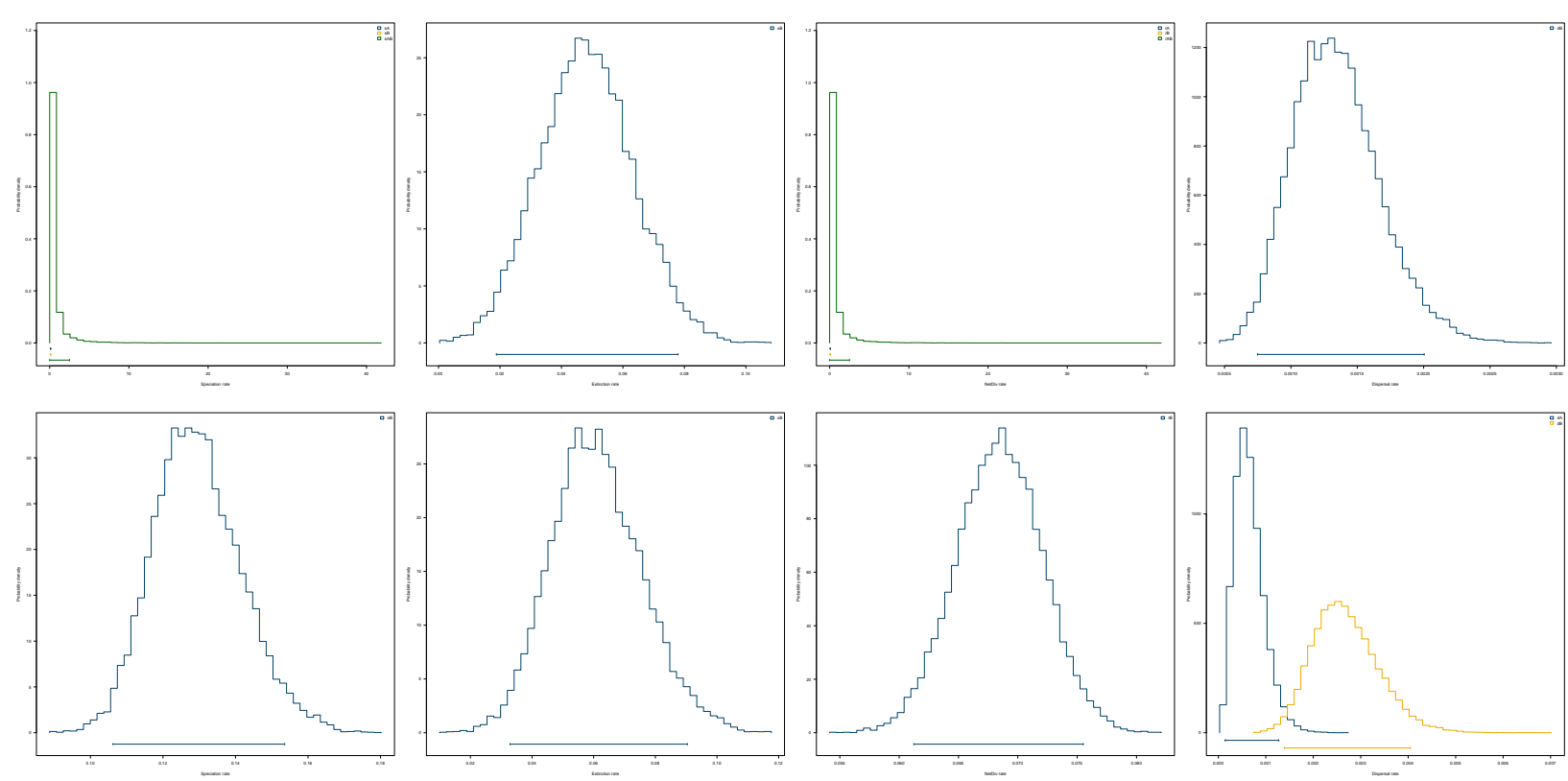

Figure 3: GeoSSE Result Dung Producers Young Tree.

Posterior distributions of area-dependent rates estimated by GeoSSE. Left to right: speciation rates, extinction rates, net diversification rates (speciation - extinction), dispersal rates. Top: rates in areas with large and medium sized mammals and high and intermediate droppingsdiversity (Afro-Eurasia and Americas, blue), and rates in areas with small sized mammals and low droppings-diversity (East Gondwanan Fragments, yellow). Bottom: rates in areas with large sized mammals and high droppings-diversity (Afro-Eurasia, yellow), and rates of areas with low and medium sized mammals and low and intermediate droppings-diversity (Americas and East Gondwanan Fragments, blue). Rates of widespread taxa are colored green; where only one rate was estimated, it is colored blue. Dispersal rates of an area reflect dispersal out of said area. 

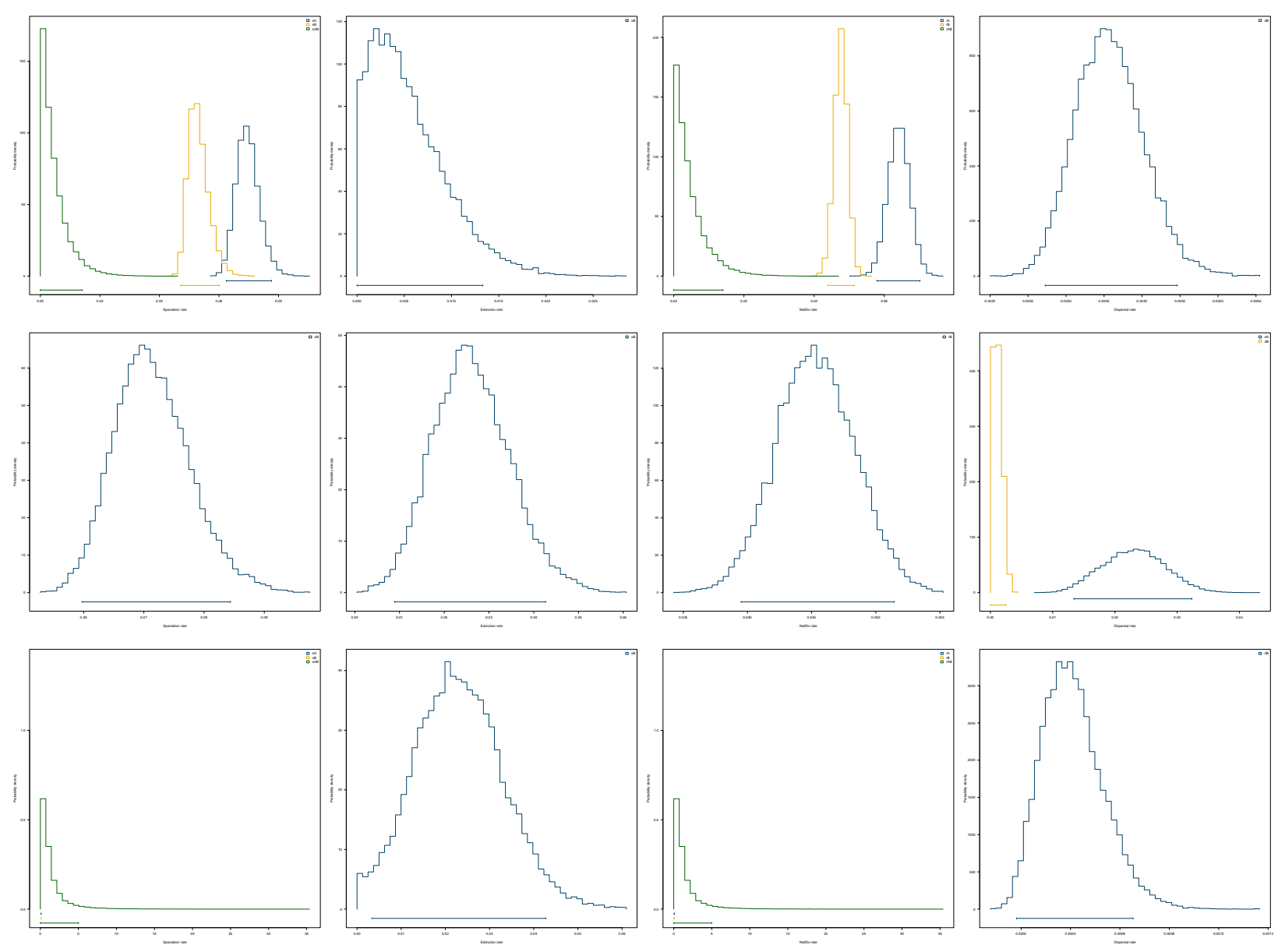

\section{Figure 4: GeoSSE Results Out-Of-Gondwana Old Tree.}

Posterior distributions of area-dependent rates estimated by GeoSSE. Left to right: speciation rates, extinction rates, net diversification rates (speciation - extinction), dispersal rates. Top: rates in Laurasia and Madagascar (blue), and rates in Gondwana (yellow). Center: rates in Laurasia (blue), and rates in Gondwana and Madagascar (yellow). Bottom: rates in Madagascar (blue), and rates in Gondwana and Laurasia. Rates of widespread taxa are colored green; where only one rate was estimated, it is colored blue. Dispersal rates of an area reflect dispersal out of said area. 

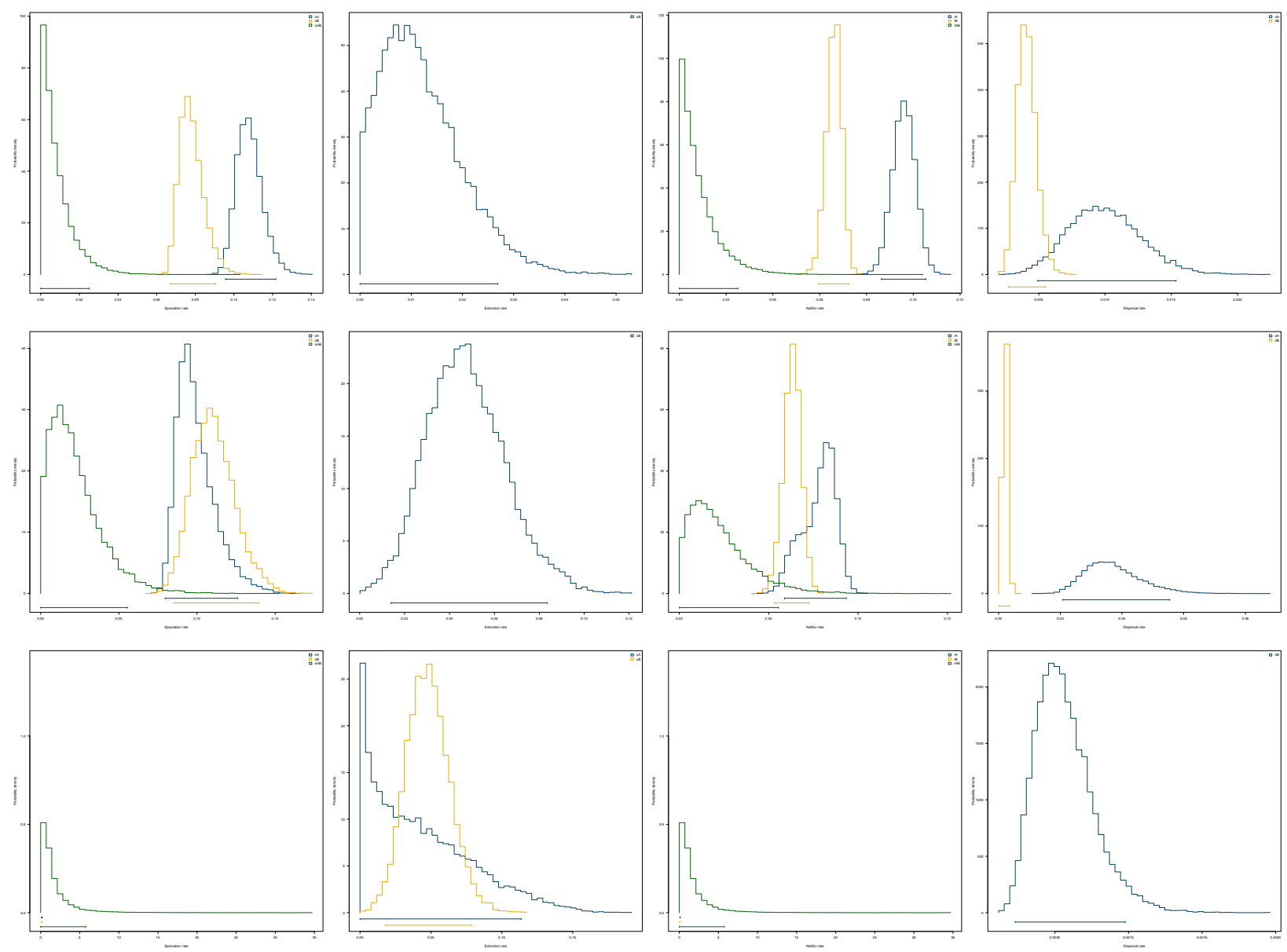

Figure 5: GeoSSE Results Out-Of-Gondwana Young Tree.

Posterior distributions of area-dependent rates estimated by GeoSSE. Left to right: speciation rates, extinction rates, net diversification rates (speciation - extinction), dispersal rates. Top: rates in Laurasia and Madagascar (blue), and rates in Gondwana (yellow). Center: rates in Laurasia (blue), and rates in Gondwana and Madagascar (yellow). Bottom: rates in Madagascar (blue), and rates in Gondwana and Laurasia. Rates of widespread taxa are colored green; where only one rate was estimated, it is colored blue. Dispersal rates of an area reflect dispersal out of said area. 